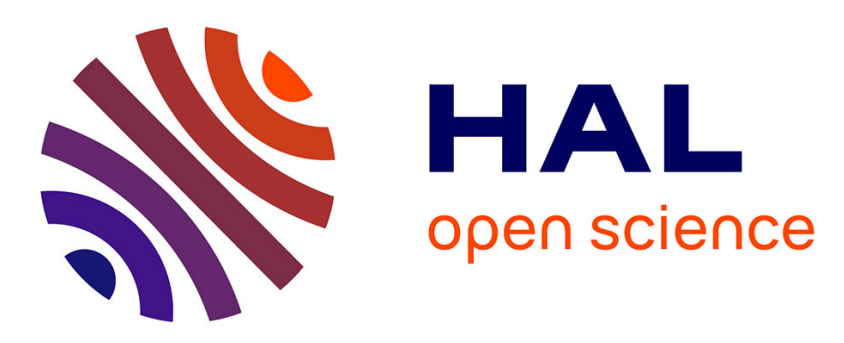

\title{
Total Synthesis of Tiacumicin B: Implementing Hydrogen Bond Directed Acceptor Delivery for Highly Selective $\beta$-Glycosylations
}

Stéphanie Norsikian, Cedric Tresse, Marc François-eude, Louis Jeanne-julien, Guillaume S Masson, Vincent Servajean, Grégory Genta-Jouve, Jean-marie Beau, Emmanuel Roulland

\section{To cite this version:}

Stéphanie Norsikian, Cedric Tresse, Marc François-eude, Louis Jeanne-julien, Guillaume S Masson, et al.. Total Synthesis of Tiacumicin B: Implementing Hydrogen Bond Directed Acceptor Delivery for Highly Selective $\beta$-Glycosylations. Angewandte Chemie International Edition, 2020, 59 (16), pp.66126616. 10.1002/anie.202000231 . hal-02991902

\section{HAL Id: hal-02991902 https://hal.science/hal-02991902}

Submitted on 6 Nov 2020

HAL is a multi-disciplinary open access archive for the deposit and dissemination of scientific research documents, whether they are published or not. The documents may come from teaching and research institutions in France or abroad, or from public or private research centers.
L'archive ouverte pluridisciplinaire HAL, est destinée au dépôt et à la diffusion de documents scientifiques de niveau recherche, publiés ou non, émanant des établissements d'enseignement et de recherche français ou étrangers, des laboratoires publics ou privés. 


\title{
Total Synthesis of Tiacumicin B: Implementing H-bond-Directed Acceptor Delivery for Highly Selective $\beta$-Glycosylations
}

\author{
Stéphanie Norsikian, ${ }^{*[a]}$ Cedric Tresse,${ }^{[a]}$ Marc François-Eude ${ }^{[a]}$ Louis Jeanne-Julien, ${ }^{[b]}$ Guillaume \\ Masson, ${ }^{[b]}$ Vincent Servajean, ${ }^{[a]}$ Grégory Genta-Jouve, ${ }^{[b]}$ Jean-Marie Beau, ${ }^{[a][c]}$ and Emmanuel \\ Roulland $^{*[b]}$
}

Dedicated to Professor Henri-Philippe Husson

\begin{abstract}
We report a total synthesis of tiacumicin $B$, a natural macrolide whose remarkable antibiotic properties are used to treat severe intestinal infections. The strategy is in part based on our experience of the synthesis of the tiacumicin $B$ aglycone, and on the decisive use of sulfoxides as anomeric leaving-groups in $\mathrm{H}$-bondmediated Aglycone Delivery (HAD). This new HAD variant permitted highly $\beta$-selective rhamnosylation and noviosylation. To increase convergence, the rhamnosylated C1-C3 fragment thus obtained was anchored to the C4-C19 aglycone fragment by adapting the reliable Suzuki-Miyaura cross-coupling used for the aglycone synthesis. Ring-size selective macrolactonization provided a compound engaged directly in the noviolysation step with a virtually total $\beta$ selectivity. The final efficient removal of all the protective groups (PGs) provided synthetic tiacumicin $B$.
\end{abstract}

Tiacumicin B (Tcn-B, 1) - also known as clostomicin B1, fidaxomicin or lipiarmycin A3 - (Scheme 1), is a molecule isolated for the first time in 1975 from Dactylosporangium aurantiacum, an actinobacterium. ${ }^{[1]}$ Consisting of an 18-membered macrolactonic core decorated by two rare sugars (D-noviose and D-rhamnose) attached through $\beta$ glycosidic bonds, displaying 14 stereogenic centers and several polysubstituted alkenes, Tcn-B is therefore one of the most complex antibiotic-macrolides known. A high degree of synthetic difficulty eventually of course arises from such a structural complexity, whose the thorny problem of the 1,2-cis glycosylations. ${ }^{[2]}$ Resistance to antibiotics has become a serious biomedical risk and a major threat to public health with sever impacts on the economy. In this context the finding of new antibiotics with new biological targets is essential. Tcn-B is one of them and received a fast-track FDA approval in 2011 for the treatment of frequently nosocomial and fatal gut infections associated with Clostridium difficile. ${ }^{[3]}$ Tcn-B eradicates bacteria by inhibiting the RNA polymerase, targeting the "switch-region" ${ }^{[4]}$ Cross-resistance with other antibiotics is very unlikely, ${ }^{[5]}$ even with rifamycin because, although close, the domains targeted do not overlap, so that rifamycin-resistant forms of Mycobacterium tuberculosis remain highly sensitive to Tcn-B. ${ }^{[6]}$ The demand for

[a] Dr. C. Tresse, Dr. M. François-Eude, V. Servajean, Prof. J.-M. Beau, Dr. S. Norsikian, Institut de Chimie des Substances Naturelles ICSN-CNRS, Centre de Recherche de Gif, Avenue de la Terrasse, 91198, Gif-sur-Yvette (France).

[b] Dr. L. Jeanne-Julien, Dr. G. Masson, Dr. G. Genta-Jouve, Dr. E. Roulland, C-TAC, CitCom, UMR 8038, CNRS-Université de Paris, Faculté de Pharmacie, 4, avenue de l'Observatoire, 75006, Paris (France)

[c] Prof. J.-M. Beau, Laboratoire de Synthèse de Biomolécules, ICMMO, UMR 8182, Univ. Paris-Sud and CNRS, Université ParisSaclay, F-91405 Orsay, France

E-mail : emmanuel.roulland@parisdescartes.fr Supporting information for this article is given via a link at the end of the document.((Please delete this text if not appropriate))
Tcn-B analogues is therefore strong, which implies setting reliable total synthesis pathways. The daunting structure of Tcn-B being in addition very inspiring in the eyes of synthesis chemists, several renowned research groups have embarked in the adventure of its total synthesis. ${ }^{[7]}$ In 2015 Gademann $^{[8]}$ and Altmann, ${ }^{[9]}$ published the firsts syntheses of the aglycone of Tcn-B, $\mathrm{Zhu}^{[10]}$ reporting the synthesis of a diastereomer. Nonetheless, only Gademann had so far been capable of completing the total synthesis of Tcn-B, bringing the following answers to the $\beta$-glycosylations problem: ${ }^{[11,12]}$ a) The Helferich's protocol (activating agent: $\left.\mathrm{HgO}_{\text {(excess) }} / \mathrm{HgBr}_{2(\text { cat })}\right)^{[13]}$ was used to noviosylate the $\mathrm{C} 4-\mathrm{C} 13$ aglycone fragment $(\alpha / \beta: 1 / 3, \beta: 54 \%)$, as the cyclic aglycone gave only $\alpha$ adducts whatever conditions used. b) The rhamnosylation was carried out on the macrolide, using an imidate donor $(\alpha / \beta: 1 / 4$, $\beta: 62 \%$ ). Following similar strategies, Gademann also synthesized three congeners of Tcn-B: tiacumicin $A,{ }^{[12]}$ and mangrolide $A^{[14]}$ and D. ${ }^{[15]}$ In 2019, de Brabander also reported a total synthesis of mangrolide $D{ }^{[16]}$ For our part, we reported two related synthetic pathways leading to the aglycone. ${ }^{[17]}$ The original strategy we designed for the synthesis of its $\mathrm{C} 12-\mathrm{C} 15$ diene region resulted in the discovery that Pd-nanoparticles catalyze the Kumada-Corriu reaction of vinylsulfides, ${ }^{[18]}$ and led us to propose a mechanism for the Grigg's allene/alkyne cross-coupling based on DFT calculations. $^{[19]}$

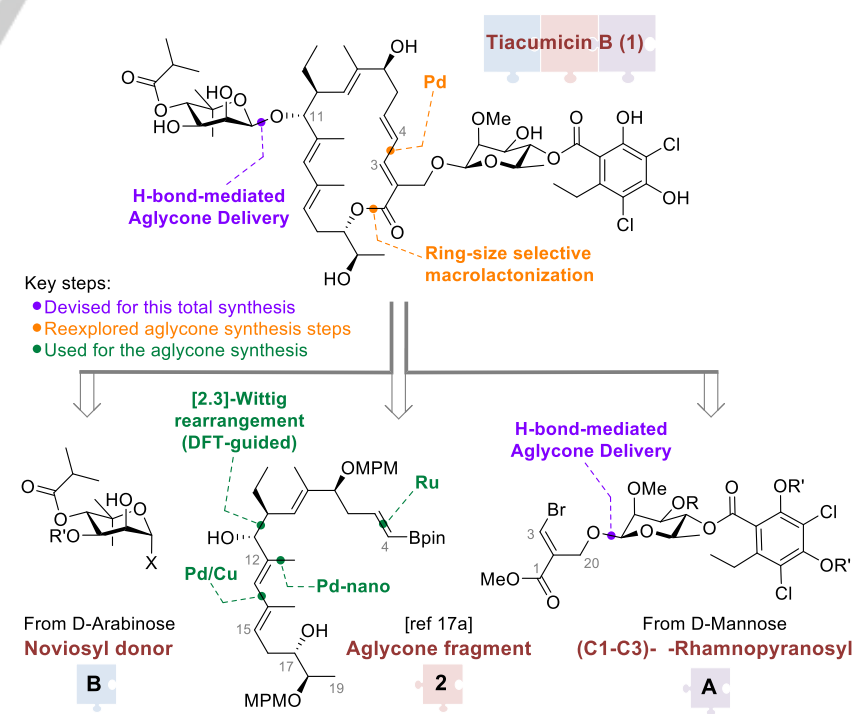

Scheme 1. Tiacumicin B (1) and our retrosynthetic analysis

The new total synthesis of tiacumicin B (1) we depict here is based on strategic and methodological innovations that allowed an 
original and selective assemblage of the three main regions of the molecule (Scheme 1). It naturally relies on our synthesis of the Tcn-B aglycone, whose strategy had been designed with an eye to the total synthesis. Originally, we had imagined glycosylating our aglycone sequentially, a probably viable pathway. However, we finally opted for a less traditional but more convergent retrosynthetic plan in which Tcn-B was disconnected into fragments $\mathbf{A}, \mathbf{B}$, and the known $2,^{[17 \mathrm{a}]}$ equivalent in size and complexity. We chose to assemble fragment $\mathbf{A}$ together with fragment 2 first, then close the macrolactone, and install fragment B at the very end. The Suzuki coupling developed during our aglycone synthesis ${ }^{[17 \mathrm{a}]}$ was considered robust enough to allow assembling fragments $\mathbf{2}$ with fragment $\mathbf{A}$, instead of the small silylated C1-C3 fragment formerly involved, ${ }^{[17 \mathrm{a}]}$ adding thus convergence. This approach reduces risks of failure since rhamnosylation conditions needed for the synthesis of $\mathbf{A}$ can be developed using as acceptor the structurally simple $\mathrm{C} 1-\mathrm{C} 3$ fragment. Complete ring-size selectivity had been observed previously during the aglycone macrolactonization. Applied to this total synthesis, this step should provide a monoglycosylated macrolactone bearing at $\mathrm{C} 11$ an unprotected $\mathrm{OH}$ directly ready for the $\beta$-noviosylation step. This exciting scenario was nonetheless uncertain for at least three reasons: $a$ ) noviosylation is a very late step, b) a high $\beta$-selectivity is required, and $c$ ) this macrolactone has been described as a reluctant glycosylation acceptor. ${ }^{[12]}$

To prepare fragment $\mathbf{A}$ we considered using a $\beta$-selective glycosylation of acceptor $\mathbf{1 8}^{[20]}$ (Scheme 3 ) by the phenylthiorhamnosyl donor 16 that bears a picoloyl group (Pico) at $O-3$ (Scheme 2).

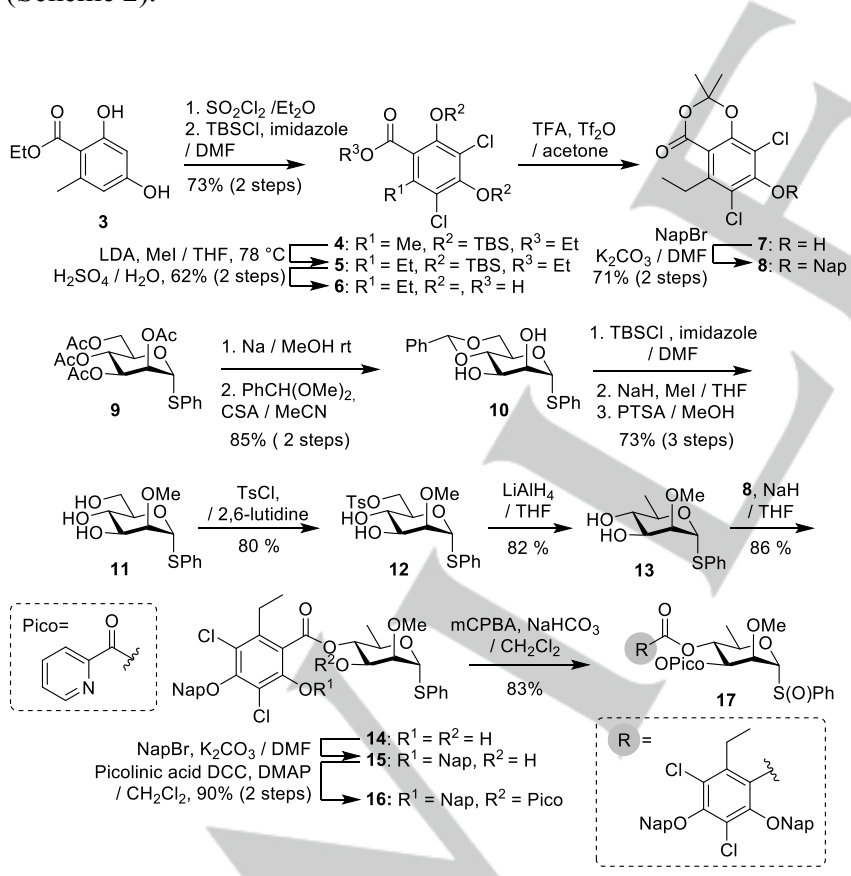

Scheme 2. Syntheses of rhamnopyranosyl donors 16 and 17. TFA: trifluoroacetic acid, NapBr: 2-naphthalene-methyl-bromide, LDA: lithium di-isopropylamide, CSA: camphorsulfonic acid, PTSA: paratoluene sulfonic acid DCC: dicyclohexylcarbodiimide, DMAP: 4-dimethylaminopyridine, $m$-CPBA: 3chloroperoxybenzoic acid.
As described by Demchenko, ${ }^{[21]}$ a remotely positioned Pico group can direct, through intermolecular H-bonding, a selective facial attack on the glycosyl donor. We started with the synthesis of the homodichloro orsellinate attached to the rhamnoside. Commercially available orcellinate $\mathbf{3}$ was dichlorinated, and both phenols were TBS-protected providing 4. The benzylic methyl group was deprotonated with LDA then methylated giving $\mathbf{5}$. Acidic hydrolysis led to deprotected carboxylic acid $\mathbf{6}$ that upon a treatment with acetone and $\mathrm{Tf}_{2} \mathrm{O}$ in trifluoroacetic acid furnished cyclic ester 7. The remaining free phenol of 7 was protected, supplying 2-naphthalene-methyl (Nap) ether 8.

We then addressed the rhamnosyl donor synthesis starting from phenyl-2,3,4,6-tetra- $O$-acetyl-1-thio- $\alpha$-D-manopyranoside $\quad 9$ (Scheme 2). Diol 10 was obtained through Zemplén deacetylation and 4,6-benzylidene formation. Then $\mathbf{1 0}$ was selectively TBSprotected at $O-3$, methylated at $O-2$, and deprotected furnishing triol 11. Selective tosylation in 2,6-lutidine gave 12, whose reduction with LAH provided the desired rhamnose derivative $\mathbf{1 3}$. Gademann's conditions allowed assembling ester $\mathbf{8}$ together with diol 13 giving selectively $14 .^{[11]}$ The free phenol of 14 was protected as a Nap ether 15, and the rhamnoside $O-3$ position was esterified with picolinic acid. This led to the expected donor $\mathbf{1 6}$ ready for the glycosylation of alcohol $\mathbf{1 8}^{[22]}$ (Scheme 3 ).
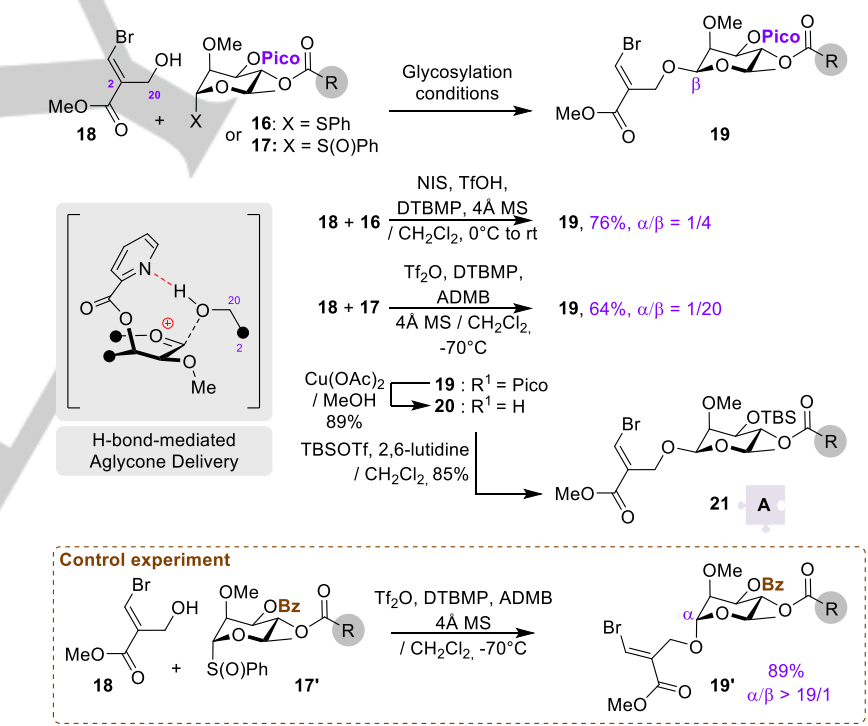

Scheme 3. Glycosylation conditions and synthesis of fragment A. NIS: Niodosuccinimide, DTBMP: 2,6-di-terbutyl-4-methylpiridine, ADMB: 4-allyl-1,2dimethoxybenzene.

Initial glycosylation attempts carried out in 1,2-dichloroethane with dimethyl(methylthio)sulfonium triflate, a classical promoter of $\mathrm{H}-$ bond-mediated Aglycone Delivery (HAD) ${ }^{[21]}$ were disappointingly unsuccessful. First promising coupling results of donor $\mathbf{1 6}$ with acceptor 18 were obtained using $N$-iodosuccinimide (1 equiv/donor) and triflic acid (0.92 equiv/donor) ${ }^{[23]}$ in $\mathrm{CH}_{2} \mathrm{Cl}_{2}$ at $40{ }^{\circ} \mathrm{C}$ to $\mathrm{rt}$ and produced $19(76 \%, \alpha / \beta: 1 / 4),{ }^{[24]}$ whose anomers was separated by prep-HPLC. Seeking much higher $\beta$-selectivity, we shifted to sulfoxide $\mathbf{1 7}$ featuring an anomeric leaving-group 
never used before in $\mathrm{HAD}$. In this case, donor 17 (1.7 eq.) was activated using $\mathrm{Tf}_{2} \mathrm{O}$ in $\mathrm{CH}_{2} \mathrm{Cl}_{2}$ at $-70{ }^{\circ} \mathrm{C}$ in the presence of the acceptor 18, DTBMP, and ADMB. ${ }^{[25,26]}$ We were pleased to find that the desired glycosylated compound $\mathbf{1 9}$ was formed with a high facial selectivity $(\alpha / \beta: 1 / 20)$, with $64 \%$ yield. To verify that this glycosylation well took place through $\mathrm{HAD}$, we made a control experiment using donor 17', an analog of $\mathbf{1 7}$ whose picoloyl was replaced by a benzoyl. Product 19' was the only one to form here, its $\alpha$ configuration indicating that the picoloyl group on donor $\mathbf{1 7}$ could direct remotely the nucleophilic attack to the $\beta$-face likely thanks to the formation of a H-bond. The picoloyl was easily removed from 19 with $\mathrm{Cu}(\mathrm{OAc})_{2}$, and replaced by a TBS to lead to key fragment $\mathbf{A}$ (21).

Our synthesis of aglycone fragment 2 was robust enough to be scaled up ${ }^{[17 \mathrm{a}]} \mathrm{We}$ were pleased to see that the cross-coupling of $\mathbf{2}$ with rhamnoside $\mathbf{2 1}$ proceeded cleanly requiring only slight modifications of formerly used the conditions. This convergent step provided ester $\mathbf{2 2}$ in a $79 \%$ yield (Scheme 4 ).

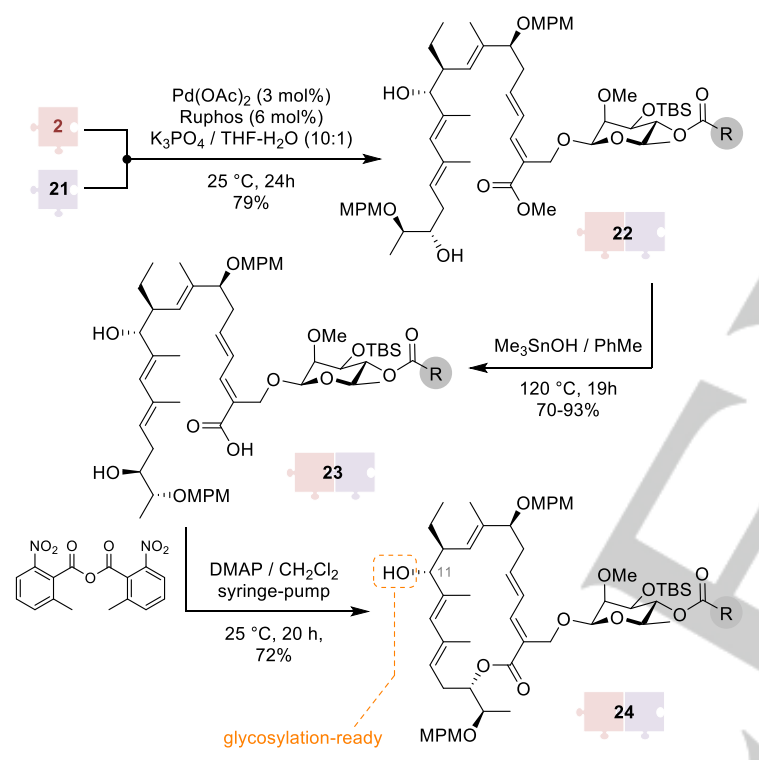

Scheme 4. Assemblage of fragments 2 and $\mathbf{A}$, and macrolactonization. MPM: 4-Methoxyphenylmethyl, Ruphos: CAS number: 787618-22-8.

A critically important selectivity was needed to convert $\mathbf{2 2}$ into seco-acid 23 since a second ester function was present on the rhamnoside moiety. This was achieved by using $\mathrm{Me}_{3} \mathrm{SnOH}$ in toluene at $120{ }^{\circ} \mathrm{C}$ giving 23 with yields of 70 to $93 \%{ }^{[27]}$ With seco-acid $\mathbf{2 3}$ in hand, we focused on the macrolactonization expecting again ring-size selectivity. However, the strict transposition of the Yamaguchi conditions ${ }^{[28]}$ we had used before, led to the desired hemi-glycosylated tiacumicin B $\mathbf{2 4}$ with only $23 \%$ yield. The Boden-Keck's protocol, ${ }^{[29]}$ allowed reaching $58 \%$ yield, but $\mathbf{2 4}$ proved to be a mixture of two products resulting from the isomerization of the C4-C5 alkene. Finally, the Shiina's conditions $\left.{ }^{[30}\right]$ allowed a far cleaner and reproducible macrolactonization into 24 with $72 \%$ yield, and an isomerization minimized at $15 \%$. Our strategy allowed keeping the $\mathrm{OH}$ at $\mathrm{C} 11$ free of protective-group throughout this synthesis, so that $\mathbf{2 4}$ could be directly engaged in the noviosylation step.

At first, to secure good $\beta$-selectivity, we had programmed anchoring the noviose using a silicon tether delivery. ${ }^{[31]}$ This strategy failed in our case, so we decided implementing again an HAD approach installing a directing picoloyl group at $O-3$ of the sugar. The required noviosyl donor was prepared from $\mathrm{D}$-arabinose 25 (Scheme 5) which was transformed into lactone $\mathbf{2 6}$ through selective acetonide protection, oxidation of the lactal, and silylation of the remaining $\mathrm{OH}$ group. Lactone $\mathbf{2 6}$ was treated with $\mathrm{MeMgBr}$, then oxidized into lactone 27 . Dibal-H reduction of $\mathbf{2 7}$ led to the corresponding lactol whose acetonide protection was removed under mild acidic conditions leading to 28. A thiophenyl group was then installed at the anomeric position giving diol 29, which was protected as bis-dichloroacetyl ester 30. Treatment by $(i \operatorname{PrCO})_{2} \mathrm{O}$ and a catalytic amount of $\mathrm{Sc}(\mathrm{OTf})_{3}$ in $\mathrm{MeCN}$ allowed the direct replacement of the TBS group by an isobutyrate leading to $31 .{ }^{[32]}$ The two dichloroacetates of $\mathbf{3 1}$ were then selectively removed with sym-collidine giving diol 32. Through the intermediate stannylene of 32, and a $\mathrm{NapBr} / \mathrm{CsF}$ treatment, a Nap PG was introduced at the $O-2$ position leading to alcohol $\mathbf{3 3}$ with an unexpectedly high selectivity. ${ }^{[33]}$

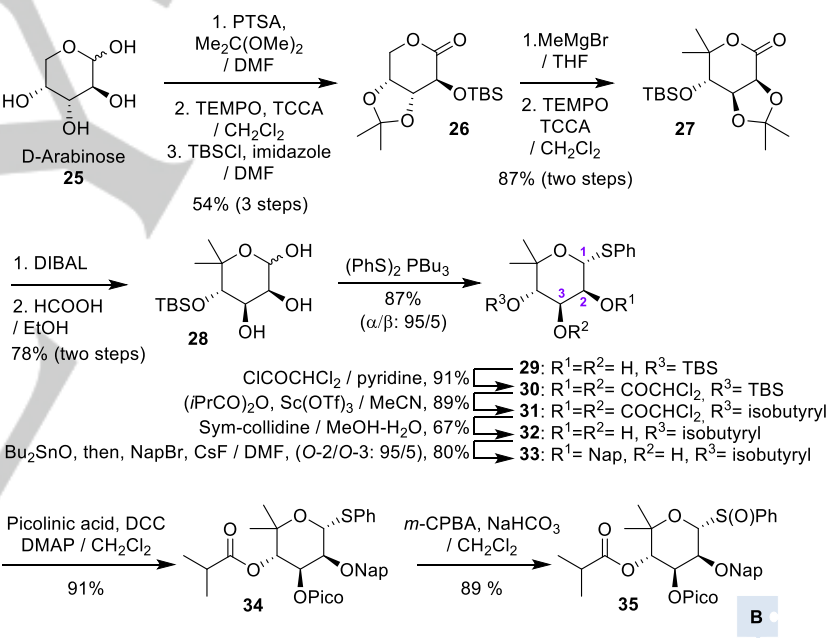

Scheme 5. Noviosyl donor synthesis. TEMPO: 2,2,6,6-Tetramethyl-1piperidinyloxy, TCCA: trichloroisocyanuric acid.

Alcohol 33 was esterified with picolinic acid using DCC to give sulfide 34, the desired noviosyl donor. Preliminary trials using $(+)-$ menthol as acceptor led predominantly to the $\beta$-adduct $(\alpha / \beta: 1 / 5)$ in $72 \%$ yield demonstrating the feasibility of this approach. Unfortunately, the reactions with macrolactonic acceptor $\mathbf{2 4}$ was unsuccessful, no glycosylated adduct being detected. ${ }^{[12]}$ The success of the above-mentioned rhamnosylation led us to consider that sulfoxide $\mathbf{3 5}$ could be a superiorly reactive donor. Under our activation conditions $\left(\mathrm{Tf}_{2} \mathrm{O}\right.$ activation of $\mathbf{3 5}$ in the presence of $\mathbf{2 4}$, DTBMP, ADMB/ $\mathrm{CH}_{2} \mathrm{Cl}_{2},-70{ }^{\circ} \mathrm{C}$ ) we were pleased to isolate the desired noviosylated product $\mathbf{3 3}$ with $68 \%$ yield, with a virtually total facial selectivity $(\alpha / \beta>1 / 20)$. ${ }^{[3]}$

The very last steps of this total synthesis consisted in removing seven PGs from compound 36: 2 MPMs, 3 Naps, 1 Pico and 1 TBS. 
First, the TBS group located on the rhamnoside moiety was cleaved using HF.NEt 3 giving alcohol 37 (Scheme 5). The 2 MPMs,
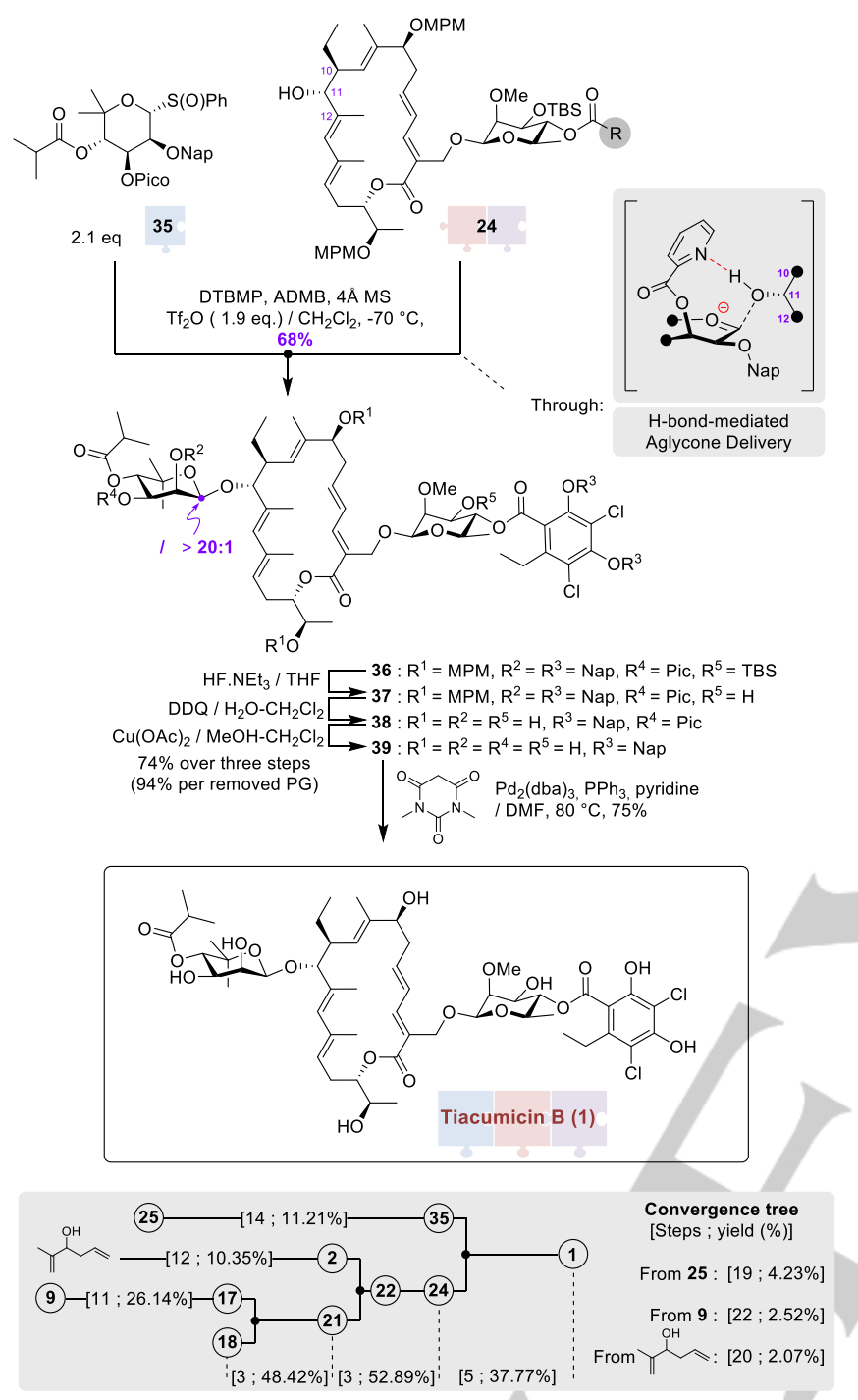

Scheme 6. Noviosylation and PGs removal. DDQ: 2,3-dichloro-5,6-dicyano1,4-benzoquinone.

as well as the Nap located at $O-2$ on the novioside, were readily oxidized by DDQ at $0{ }^{\circ} \mathrm{C}$ leading to tetraol $\mathbf{3 8}$ in 3 hours. However, the two Naps on the phenol functions of the rhamnoside proved resistant to these smooth conditions, and an extended reaction time at r.t. produced an intractable mixture of products. Nonetheless, the removal of the Pico was cleanly carried out $\left(\mathrm{Cu}(\mathrm{OAc})_{2} /\right.$ methanol$\mathrm{CH}_{2} \mathrm{Cl}_{2}, 0{ }^{\circ} \mathrm{C}$ ) giving 39. Importantly, this Pico group has to be removed after its neighboring Nap otherwise DDQ would lead to the formation of a 2-naphthylmethylidene bridge over $O-2$ and $O-3$ of the novioside. These three operations proved very clean and were performed without intermediate purification giving 39 with an overall $74 \%$ yield ( $94 \%$ per PG). Finally, we had to address what turned out to be a tricky final problem: the cleavage of the two reluctant Nap groups protecting the phenol functions. Mild Pd- catalyzed hydrogenation conditions failed at being selective. ${ }^{[35]}$ However, we had previously observed that Suzuki cross-coupling conditions used to create the $\mathrm{C} 3-\mathrm{C} 4$ bond of the aglycone led, when conducted at $80{ }^{\circ} \mathrm{C}$, to a partial loss of the Nap groups of these phenols. Exploiting this, we developed Pd-catalyzed conditions $\left(\mathrm{Pd}_{2}(\mathrm{dba})_{3} / 4 . \mathrm{PPh}_{3}, \quad\right.$ 1,3-dimethylbarbituric acid, pyridine/DMF, $80{ }^{\circ} \mathrm{C}$ ) that ultimately provided tiacumicin B (1) cleanly and with a good yield. This 4-steps removal of the 7 PGs took place with $55.5 \%$ overall yield $(91.9 \%$ per $\mathrm{PG})$. The physicochemical data of our synthetic Ten-B are strictly identical to those of the naturally occurring compound; $[\alpha]^{23}{ }_{\mathrm{D}}=-5.6 \mathrm{deg}$ $\mathrm{cm}^{3} \mathrm{~g}^{-1} \mathrm{dm}^{-1}\left(\mathrm{c}=0.41 \mathrm{~g} / 100 \mathrm{~cm}^{3}, \mathrm{MeOH}\right)$, lit.: ${ }^{[1 \mathrm{~b}]}\left([\alpha]^{23} \mathrm{D}=-5.5 \mathrm{deg}\right.$ $\mathrm{cm}^{3} \mathrm{~g}^{-1} \mathrm{dm}^{-1}\left(\mathrm{c}=1.98 \mathrm{~g} / 100 \mathrm{~cm}^{3}, \mathrm{MeOH}\right)$.

In summary, we have achieved the total synthesis of tiacumicin B (1), with as salient steps a highly $\beta$-selective rhamnosylation, a Suzuki cross-coupling that allowed assembling the rhamnoside 21 with aglycone fragment $\mathbf{2}$, a ring-size selective macrolactonization, a final and virtually totally selective $\beta$-noviosylation of the cyclic aglycone, and a successful removal of all PGs. The remarkable facial selectivity of both glycosylations relies on an $\mathrm{H}$-bonddirected effect of a remote 3-O-picoloyl group set on the incoming glycosyl acceptors, and the conjoint use of a phenylsulfoxide leaving-group. We believe that this new variant of the Demchenko procedure will prove useful to address the biological relevance of the carbohydrate moieties of tiacumicin B or other sensitive aglycones through the preparation of a set of glycosylated analogues.

\section{Acknowledgements}

We gratefully acknowledge financial supports from the French Agence Nationale pour la Recherche (ANR-14-CE16-0019-02, SYNTIA project), the CNRS, and the Universite de Paris. We thank Vincent Steinmetz for HPLC support, and Karim Hammad for NMR support.

Keywords: antibiotics $\cdot$ natural products $\cdot$ total synthesis $\cdot$ catalysis $\bullet$ enantioselective synthesis $\bullet$ glycosylation

[1] Firstly isolated: a) F. Parenti, H. Pagani, G. Beretta, J. Antibiot. 1975, 28, 247-252. b) C. Coronelli, R. J. White, G. C. Lancini, F. Parenti, J. Antibiot. 1975, 28, 253-259. c) Amura S., Imamura N., Oiwa R., Kuga H., Iwata R., Masuma R., J. Antibiot. 1986, 39, 1407-1412.d) Theriault R. J., Karwowski J. P., Jackson M., Girolami R. L., Sunga G. N., Vojtko C. M., J. Antibiot. 1987, 40, 567-574. e) Hochlowski J. E., Swanson S. J., Ranfranz L. M., Whittern D. N., Buko A. M., McAlpine J. B., J. Antibiot. 1987, 40, 575-588. f) A. Bedeschi, P. Fonte, G. Fronza, C. Fuganti, S. Serra, Nat. Prod. Commun. 2014, 9, 237-240; Some ambiguity existed concerning the structure of tiacumicin $B$ and its relatives, for clarifications see: g) W. Erb, J. Zhu, Nat. Prod. Rep. 2013, 30, 161-174.

[2] For a recent review see: S. S. Nigudkar and A. V. Demchenko, Chem. Sci. 2015, 6, 2687-2704.

[3] Traynor K., Am. J. Health Syst. Pharm. 2011, 68, 1276.

[4] a) A. Tupin, M. Gualtieri, J.-P. Leonetti, K. Brodolin, EMBO J. 2010, 29 , 2527-2537. b) M. Gualtieri, A. Tupin, K. Brodolin, J.-P. Leonetti, Int. J. Antimicrobial Agents 2009, 34, 605-616. 
[5] A. Srivastava, M. Talaue, S. Liu, D. Degen, R. Y. Ebright, E. Sineva, A Chakraborty, S. Y. Druzhinin, S. Chatterjee, J. Mukhopadhyay, Y. W. Ebright, A. Zozula, J. Shen, S. Sengupta, R. R. Niedfeldt, C. Xin, T. Kaneko, H. Irschik, R. Jansen, S. Donadio, N. Connell, R. H Ebright Current Opinion in Microbiology 2011, 14, 532-543.

[6] M. Kurabachew, S. H. Lu, P. Krastel, E. K. Schmitt, B. L. Suresh, A Goh, J. E. Knox, N. L. Ma, J. Jiricek, D. Beer, M. Cynamon, F. Petersen, V. Dartois, T. Keller, T. Dick, V. K. J. Sambandamurthy, Antimicrob. Chemother 2008, 62, 713-719.

[7] For a review on the various synthetic approaches see: E. Roulland Synthesis 2018, 50, 4189-4200.

[8] H. Miyatake-Ondozabal, E. Kaufmann, K. Gademann, Angew. Chem. Int. Ed. 2015, 54, 1933-1936. Angew. Chem. 2015, 127, 1953-1956.

[9] F. Glaus, K.-H. Altmann, Angew. Chem. Int. Ed. 2015, 54, 1937-1940. Angew. Chem. 2015, 127, 1957-1961.

[10] W. Erb, J.-M. Grassot, D. Linder, L. Neuville, J. Zhu, Angew. Chem. Int Ed. 2015, 54, 1929-1932. Angew. Chem. 2015, 127, 1949-1952.

[11] E. Kaufmann, H. Hattori, H. Miyatake-Ondozabal, K. Gademann Org. Lett. 2015, 17, 3514-3517.

[12] H. Hattori, E. Kaufmann, H. Miyatake-Ondozabal, R. Berg, K. Gademann, J. Org. Chem. 2018, 83, 7180-7205.

[13] B. Helferich, K. F. Wedemeyer, Liebigs Ann. Chem. 1949, 563, 139 145.

[14] H. Hattori, J. Roesslein, P. Caspers, K. Zerbe, H. Miyatake-Ondozabal, D. Ritz, G. Rueedi, K. Gademann, Angew. Chem. Int. Ed. 2018, 57, 11020-11024. Angew. Chem. 2018, 130, 11186-11190.

[15] H. Hattori, L. V. Hoff, K. Gademann Org. Lett. 2019, 21, 3465-3459.

[16] J. Gong, W. Li, P. Fu, J. MacMillan, J. K. De Brabander Org. Lett. 2019 21, 2957-2961.

[17] a) L. Jeanne-Julien, G. Masson, E. Astier, G. Genta-Jouve, V. Servajean, J.-M. Beau, S. Norsikian, E. Roulland Org. Lett. 2017, 19 4006 - 4009. b) L. Jeanne-Julien, G. Masson, E. Astier, G. GentaJouve, V. Servajean, J.-M. Beau, S. Norsikian, E. Roulland J. Org. Chem. 2018, 83, $921-929$.

[18] L. Jeanne-Julien, E. Astier, R. Lai-Kuen, G. Genta-Jouve, E. Roulland Org. Lett. 2018, 20, 1430-1434.

[19] L. Jeanne-Julien, G. Masson, R. Kouoi, A. Regazzetti, G. Genta-Jouve, V. Gandon, E. Roulland Org. Lett. 2019, 21, 3136-3141.

[20] See supporting informations for its preparation
[21] a) J. P. Yasomanee and A. V. Demchenko, J. Am. Chem. Soc. 2012 134, 20097-20102. b) S. G. Pistorio, J. P. Yasomanee, A. V. Demchenko, Org. Lett. 2014, 16, 716-719.

[22] See the SI for the preparation

[23] The reaction was unsuccessful with a catalytic amount of $\mathrm{TfOH}$

[24] Stereochemistry determined by measuring ${ }^{1} J_{\mathrm{C} 1, \mathrm{H} 1}$ coupling: $\approx 160 \mathrm{~Hz}$ indicates that $\mathrm{H}-1$ is axial, and $\approx 170 \mathrm{~Hz}$ equatorial.

[25 ] J. Gildersleeve, A. Smith, K. Sakurai, S. Raghavan, D. Kahne, J. Am Chem. Soc. 1999, 121, 6176-6182.

[26 ] J. Zeng, Y. Liu, W. Chen, X. Zhao, L. Meng, Q. Wan, Top Curr Chem 2018, 376, 27-59.

[27] K. C. Nicolaou, A. A. Estrada, M. Zak, S. H. Lee, B. S. Safina, Angew Chem. Int. Ed. 2005, 44, 1378-1382. Angew. Chem. 2005, 117, 14021406 .

[28] J. Inanaga, K. Hirata, H. Saeki, T. Katsuki, M. Yamaguchi, Bull. Chem. Soc. Jpn. 1979, 52, 1989-1993.

[29] a) E. P. Boden, G. E. Keck, J. Org. Chem. 1985, 50, 2394-2395. b) G E. Keck, E. P. Boden, M. R. Wiley, J. Org. Chem. 1989, 54, 896-906.

[30] I. Shiina, M. Kubota, H. Oshiumi, M. Hashizume, J. Org. Chem. 2004 69, 1822-1830.

[31] a) G. Stork, G. Kim, J. Am. Chem. Soc. 1992, 114, 1087. b) M. Bols, J. Chem. Soc., Chem. Commun. 1992, 913-914. c) J. T. Walk, Z. A. Buchan, J. Montgomery, Chem. Sci. 2015, 6, 3448-3453.

[32] S. Norsikian, I. Holmes, F. Lagasse, H. B. Kagan, Tetrahedron Lett 2002, 43, 5715-5717.

[33] A ${ }^{3} J_{1,2}$ coupling constant of $9.5 \mathrm{~Hz}$ in the ${ }^{1} \mathrm{H}$ NMR spectrum of diol 32 indicates a $\mathrm{H}-1 / \mathrm{H}-2 \mathrm{a}$ trans diaxial orientation. Therefore, the conformation of the starting diol is not a conventional ${ }^{4} \mathrm{C}_{1}$ chair but rather a ${ }^{1} \mathrm{C}_{4}$ chair certainly imposed by the presence of the gemdimethyl group. The equatorial $\mathrm{OH}$ is more accessible, which accounts for the selectivity of this protection.

[34] The $\alpha$ anomer could not be detected in ${ }^{1} \mathrm{H}$ NMR spectrum.

[35] A B. Smith, III, C. Sfouggatakis, C. A. Risatti, J. B. Sperry, W. Zhu, V. A. Doughty, T. Tomioka, D. B. Gotchev, C. S. Bennett, S. Sakamoto, O Atasoylu, S. Shirakami, D. Bauer, M. Takeuchi, J. Koyanagi, Y. Sakamoto, Tetrahedron, 2009, 65, 6489-6509. 
Entry for the Table of Contents (Please choose one layout)

\section{COMMUNICATION}

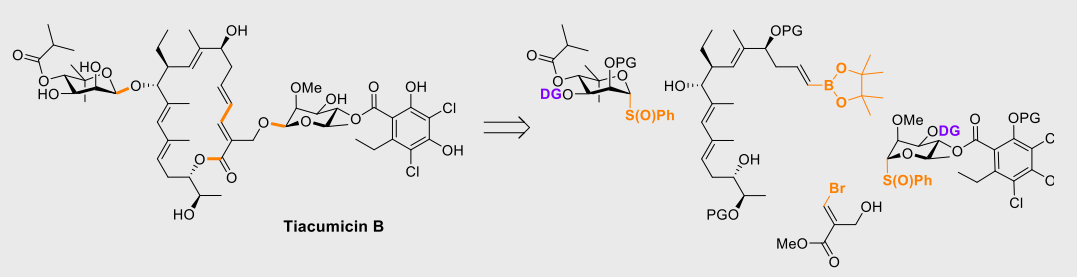

Stéphanie Norsikian, ${ }^{*}$ Cedric Tresse, Marc François-Eude, Louis JeanneJulien, Guillaume Masson, Vincent Servajean, Grégory Genta-Jouve, JeanMarie Beau, and Emmanuel Roulland*

Page No. - Page No.

Total Synthesis of Tiacumicin B: Implementing $\mathrm{H}$-bond-Directed Acceptor Delivery for Highly Selective $\beta$-Glycosylations 